Research Article

\title{
Study on the Relationship between Stress and Charge of Coal Mass under Uniaxial Compression
}

\author{
Gang Wang $\mathbb{D}^{1},{ }^{1}$ Yishan Pan $\mathbb{D},{ }^{1,2}$ Xiaochun Xiao $\mathbb{D}^{1},{ }^{1}$ Di Wu, ${ }^{1}$ Hongrui Zhao $\mathbb{D},{ }^{3}$ \\ Aiwen Wang, and Xin Ding (iD) \\ ${ }^{1}$ School of Mechanics and Engineering, Liaoning Technical University, Fuxin 123000, China \\ ${ }^{2}$ School of Physics, Liaoning University, Shenyang 110036, China \\ ${ }^{3}$ Coal Science and Technology Group Shenyang Research Institute, Shenyang 110015, China
}

Correspondence should be addressed to Yishan Pan; panyish_cn@sina.com

Received 27 May 2019; Revised 30 July 2019; Accepted 11 August 2019; Published 21 October 2019

Academic Editor: Luca Landi

Copyright (c) 2019 Gang Wang et al. This is an open access article distributed under the Creative Commons Attribution License, which permits unrestricted use, distribution, and reproduction in any medium, provided the original work is properly cited.

This paper presents a new method to identify the stress concentration degree and stress distribution characteristics in front of working face in coal mine, based on the close relationship between charge and stress during fracture of coal mass. This method overcomes many disadvantages of conventional stress-monitored methods. First, the stress and charge relationship of coal mass was established through damage theory and statistical strength theory. Then, the relationship between stress and charge was studied by a laboratory test, and finally, the field charge monitoring test was performed. The results show that there is a nonlinear relationship between loading stress $(\sigma)$ and cumulative charge $(Q)$, which can be represented by polynomials. The fitting results of the laboratory test between $\sigma$ and $Q$ conform to a cubic polynomial function, $Q=a \sigma^{3}+b \sigma^{2}+c \sigma+d$. It verifies the rationality of the theoretical relationship formula. The field monitoring results show that average charge is great and cumulative charge changes from rapid upward to sharp upward before roof falling. The magnitude and position of average charge and the upward trend of cumulative charge can be used to identify the stress concentration and stress distribution in front of working face, and the abnormal stress area can be predicted. The results can provide certain guidance for the forecast of rock burst in coal mine.

\section{Introduction}

Nowadays, the threat of rock burst is increasingly intensifying with the increase of mining depth and intensity. As a result, research on the prediction of rock burst is extremely urgent $[1,2]$.

The occurrence of rock burst is a result of multiple factors, including geostress, mining depth, coal-rock impact tendency, geological structures, overlying strata structure, and mining layout. Among these factors, high-stress environment is the principal consideration. The mechanism of rock burst induced by the combination of coal mining dynamic load and high static stress has been recognized by scholars [3]. Therefore, the accurate prediction of high static stress area of underground coal and rock mass can guide the relief area of pressure relief with a large diameter drilling hole and coal mass blasting measures and thus can effectively prevent and control the rock burst.
The study of effective stress monitoring methods has become an important scientific issue to ensure the safe and efficient mining of coal resources. At present, conventional methods of monitoring stress mainly include drilling cuttings and stress online monitoring $[4,5]$. The former method requires manual operation, and it is time-consuming, laborious, and greatly influenced by human factors, resulting in low accuracy and reliability of monitoring data. Although the online stress monitoring method has a high accuracy of monitoring data, it has some disadvantages, such as complicated installation procedure, astronomical cost, and small coverage area. Therefore, a more effective monitoring method is required.

The existing research results show that there are charges in the process of deformation and failure of coal and rock mass due to the piezoelectric effect, friction, and microfracture leading to charge separation at the crack tip and so on [6-9]. The charge signals are closely related to the 
dynamic process of coal and rock, and there is a great deal of information about the mechanical process of deformation and fracture of coal and rock mass. The charges can be extracted and analyzed by a high-sensitivity charge collection system, forming a charge induction method for monitoring coal and rock fracture instability.

Many scholars focused on charge induction technology. Nitsan [10] studied the piezoelectric effect of rock and obtained that when rock containing quartz and other hard piezoelectric materials break down, there is a charge-induced signal in the radio frequency band. Ogawa et al. [11] found that the opposite polarity charges were produced on both sidewalls of the original crack wall during the fracture process of piezoelectric rock materials. Kuksenko et al. [12] measured the induced charge with an electrometer when marble was loaded and found that the induced charge increased sharply when the rock was suddenly loaded or unloaded. Varotsos et al. [13] found that there are lowfrequency and instantaneous pulse charge signals before the earthquake and the duration of the signal was longer. Vallianatos et al. [14-16] presented the MCD model for the generation of electric current in rocks under stress, which was influenced by the motion of charge bearing dislocations. Within the MCD model, for the first time, the relationship between current density and strain rate was demonstrated and used as a prominent mechanism for the production of electric earthquake precursors. Triantis et al. [17-19] found a linear relationship between charge signal and deformation by applying uniform velocity stress to the rock during the application of the pressure-stimulated current (PSC) technique. Sun et al. [20] found that when diorite, marble, and limestone were loaded, the fractured rock was charged in the early stage, and according to the magnetic field intensity of the main fracture, the charge of fracture surface was calculated to be $5.2 \times 10^{-4} \mathrm{C}$ and the charge surface density was $1.4 \times 10^{-2} \mathrm{C} / \mathrm{m}^{2}$. He et al. [21] proved that there is electromagnetic radiation in the process of deformation and failure of coal through experimental research, and the premise and basis of electromagnetic radiation is the separation of charge. Lv et al. [22] discussed the formation mechanism of the interface potential barrier of microcracks in coal and rock mass. It is believed that under external loads, slip, dislocation, and inhomogeneous deformation of crack interface and tip lattice result in charge breakthrough and jump, and potential barrier energy is formed at the crystal interface. Pan et al. [23] studied the charge law of coal mass under tensile failure. The abnormal area of charge signals corresponded to the stress mutation stage in the coal and rock splitting test. The free charge produced by tensile failure of coal mass was more abundant than that of sandstone and mudstone. Wang et al. [24] studied the failure characteristics and charge law of coal mass under uniaxial loading and found that the charge signal law corresponding to different failure characteristics was different.

Although much research has been done on the charge signal law of coal and rock mass under external load, the theoretical study on the stress and charge relationship and the experimental study on the quantitative relationship between stress and charge parameters of coal mass have not been reported yet. These are important preconditions for predicting rock burst by the charge induction method. Hence, in this work, the stress and charge relationship formula of coal mass under uniaxial compression is established, the quantitative relationship between stress and cumulative charge is obtained through laboratory experiments, and the field test of charge monitoring is carried out by the independently developed device. The research results can provide a new idea for the prediction of stress concentration degree and stress distribution characteristics of coal and rock mass, so as to provide some references for the prevention of rock burst.

\section{Stress and Charge Relationship Analysis of Coal Mass under Uniaxial Compression}

2.1. Preliminary Study on Charge Generation Mechanism of Coal Rock Fracture. As shown in Figure 1, when the coal rock is fractured under load, dislocation and slip are generated on the surface and the tip of crack after initiation of new crack and the propagation of primary crack. As a result, the friction between crack interfaces is induced. The positive and negative charges are separated from the process migrate, aggregate, and mutate in different directions, and the macroscopic phenomenon is the nonuniform charge separation on the crack interfaces. At the same time, due to the movement and transfer of atoms, vacancies are formed. Atoms move to different vacancies, and their repeated movement and transfer result in the formation of micropotential barriers at different charge accumulation interfaces. The charge generation mechanism in the coal-rock fracture process can be explained by the theory of electricity generation of crack slip friction and the change of interfacial potential barrier of microcracks [25].

\subsection{Stress and Charge Relationship Formula Analysis.}

Because the charge is related to the deformation and fracture of coal and rock and the internal damage process of coal and rock under compression, damage theory can be applied to study the relationship between stress and charge [26, 27]. It is assumed that the coal and rock material can be regarded as composed of a number of microelements with different defects. Moreover, the microelement can be regarded as small enough from the macroscopic, and its internal mechanical properties can be regarded as uniform. At the same time, from the mesoscopic point of view, the microelement can also be considered to be of large size to reflect the statistical average properties of materials due to enough mesostructural information.

Assuming mesoelement strength of coal and rock conforms to Weibull distribution [28], the probability density function of Weibull distribution is

$$
\varphi(\varepsilon)=\frac{m}{\varepsilon_{0}}\left(\frac{\varepsilon}{\varepsilon_{0}}\right)^{m-1} \exp \left[-\left(\frac{\varepsilon}{\varepsilon_{0}}\right)^{m}\right]
$$

where $\varepsilon_{0}$ is the distribution scale of Weibull distribution, $m$ is the morphological parameter expressed in the form of strain, 


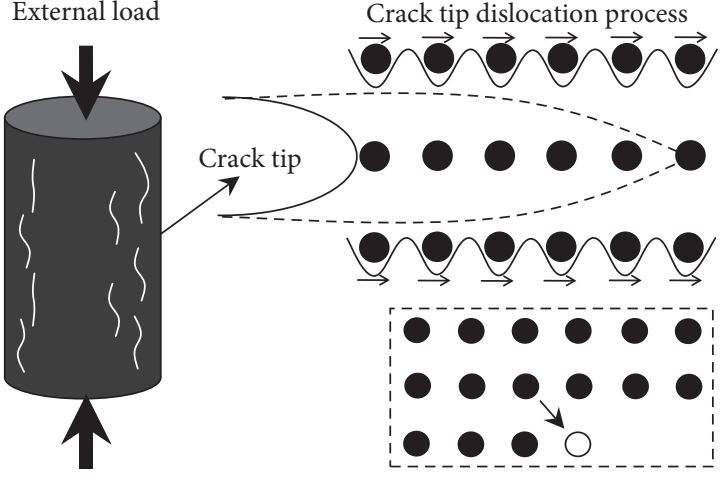

External load
Vacancy formation

FiguRe 1: Mechanism of charge generation with crack sliding and friction interface dislocation potential barrier.

and $\varepsilon$ is the strain of microelement of coal and rock under uniaxial compression. $\varphi(\varepsilon)$, the probability of failure of microelement, reflects the damage degree of the specimen microscopically and can be used to estimate the failure of microelements macroscopically.

It is assumed that a certain number of charge events will be generated once the microelement is destroyed, which will contribute to the total number of charge events. Then, the probability of the number of charge events in the process of deformation and failure of coal and rock mass can be expressed by formula (1). At the same time, it is assumed that the microelement cannot recover its strength once it is broken. That is to say, the damage of coal and rock mass is irreversible in the process of deformation and fracture. Then, the number of charge events, $N$, generated can be determined based on charge events per unit volume, $n$, and the failure volume, $\Delta V$, as follows:

$$
N=n \Delta V
$$

Assuming that the volume of the whole coal and rock mass is $V$ and the total number of charge events accumulated during the complete failure of the coal and rock mass is $N_{0}$,

$$
N=\frac{N_{0}}{V} \Delta V .
$$

According to the Weibull distribution, when the strain of coal and rock mass increases, $\Delta \varepsilon$, the volume $\Delta V$ of failure of coal and rock mass is

$$
\Delta V=V \int_{\varepsilon}^{\varepsilon+\mathrm{d} \varepsilon} \varphi(x) \mathrm{d} x .
$$

Therefore, when the strain of coal and rock mass increases, $\Delta \varepsilon$, the number of charge events $N$ is

$$
N=N_{0} \int_{\varepsilon}^{\varepsilon+\mathrm{d} \varepsilon} \varphi(x) \mathrm{d} x .
$$

Similarly, when the strain of coal and rock mass during loading is $\varepsilon$, the cumulative number of charge events $\sum N$ is

$$
\sum N=N_{0} \int_{0}^{\varepsilon} \varphi(x) \mathrm{d} x .
$$

When the uniaxial compression deformation of coal and rock mass increases from $\varepsilon$ to $\varepsilon+\mathrm{d} \varepsilon$, the corresponding stress increases from $\sigma$ to $\sigma+\mathrm{d} \sigma$. The relation between the charge event number $N$ and the loading principal stress $\sigma_{1}$ is

$$
\begin{aligned}
N= & N_{0} \int_{\varepsilon}^{\varepsilon+\mathrm{d} \varepsilon} \varphi(x) \mathrm{d} x=N_{0} \int_{\sigma}^{\sigma+\mathrm{d} \sigma} \frac{m}{\varepsilon_{0}}\left(\frac{\sigma_{1}}{E \varepsilon_{0}}\right)^{m-1} \\
& \cdot \exp \left[-\left(\frac{\sigma_{1}}{E \varepsilon_{0}}\right)^{m} \mathrm{~d} \sigma\right],
\end{aligned}
$$

where $E$ is the elastic modulus of microelement.

Then, the uniaxial compression deformation of coal and rock mass increases from 0 to $\varepsilon$, the corresponding stress increases from 0 to $\sigma$. The relation between the charge event number $\sum N$ and the loading principal stress $\sigma_{1}$ is

$$
\sum N=N_{0} \int_{0}^{\varepsilon} \varphi(x) \mathrm{d} x=N_{0} \int_{0}^{\sigma} \frac{m}{\varepsilon_{0}}\left(\frac{\sigma_{1}}{E \varepsilon_{0}}\right)^{m-1} \exp \left[-\left(\frac{\sigma_{1}}{E \varepsilon_{0}}\right)^{m}\right] \mathrm{d} \sigma .
$$

For simplicity of calculation, let $m=1$, then

$$
\begin{aligned}
\sum N & =N_{0} \int_{0}^{\varepsilon} \varphi(x) \mathrm{d} x=N_{0} \int_{0}^{\sigma} \frac{1}{\varepsilon_{0}} \exp \left[-\left(\frac{\sigma_{1}}{E \varepsilon_{0}}\right)\right] \mathrm{d} \sigma \\
& =E N_{0}\left\{1-\exp \left[-\left(\frac{\sigma}{E \varepsilon_{0}}\right)\right]\right\} .
\end{aligned}
$$

The following formula (10) can be obtained by expanding formula (9) according to Taylor series and taking polynomial

$$
\sum N=a_{n} \sigma^{n}+a_{n-1} \sigma^{n-1}+\cdots+a_{1} \sigma+a_{0},
$$

where $a_{n}, a_{n-1}, \ldots, a_{0}$ are constant.

It can be seen that there is a nonlinear relationship between the cumulative charge events and the loading stress of coal and rock mass under uniaxial compression, which can be regarded as the $n$-th polynomial relationship.

In the process of deformation and failure of coal and rock microelement, a certain amount of charges are accumulated for each charge event. The more charge events are generated per unit time, the more charges are accumulated. The charge of each charge event is $q$, and the loading stress is $\sigma$, so the total cumulative charge $Q$ is

$$
Q=\sum N q \text {. }
$$

The relationship between stress and total charge in uniaxial compression can be obtained by introducing formula (10) into formula (11) as follows:

$$
Q=f(\sigma)=b_{n} \sigma^{n}+b_{n-1} \sigma^{n-1}+\cdots+b_{1} \sigma+b_{0},
$$

where $b_{n}, b_{n-1}, \ldots, b_{0}$ are constant.

From the above theoretical analysis, it can be seen that there is a polynomial relationship between loading stress and 
cumulative charge of coal and rock mass under uniaxial compression.

\section{Experimental Research on the Relationship between Stress and Charge of Coal Mass under Uniaxial Compression}

3.1. Sample Preparation. Coal blocks were taken from a mine in Henan. In the laboratory, coal blocks were prepared into a standard sample. The diameter of the sample was $50 \mathrm{~mm}$, and the length was $100 \mathrm{~mm}$. A total of 10 coal samples were prepared, as shown in Figure 2.

3.2. Experiment System. As shown in Figure 3, the experiment system includes a loading system, a shielding system, and a charge signal monitoring system.

A DCS-300 digital hydraulic servo test machine was used for the uniaxial compression test, and load and displacement data acquisition processes were used to obtain the measurements automatically, which were made by MTS Systems (China) Co., Ltd, GuangDong Province, China. The machine has a compression capacity of $600 \mathrm{kN}$. The shielding system is a self-developed multifunctional cylindrical shielded steel cylinder with a diameter of $20 \mathrm{~cm}$ and a height of $30 \mathrm{~cm}$, and the insulating paper was used to insulate the bearing plate and coal samples. The charge signal monitoring system consisted of a noncontact charge induction probe, a charge amplifier, and a data acquisition instrument. The type of charge amplifier was ICA101, which was made in Hunan Province, China, with a length of $15 \mathrm{~cm}$, width of $10 \mathrm{~cm}$, and height of $3 \mathrm{~cm}$. The basic sketch of charge amplifier is shown in Figure 4, and the sensor frequency was $1 \sim 1000 \mathrm{~Hz}$ and the sensitivity peak $>75 \mathrm{~dB}$.

3.3. Experiment Principle and Method. In Figure 4, the coal mass generates free charge due to internal crack propagation and friction under external load. When charged particles on crack surface pass through the sensitive element of the charge induction probe, the surface of sensitive element produces an equivalent of heterogeneous induced charges under the action of the charge induction. When the charged particles on the crack surface are far away from the sensitive element of the charge induction probe, the internal charge restores to equilibrium state. The charge amplifier can convert and amplify the induced weak charge signal into voltage signal in a certain proportional relationship. Then, voltage signal can be collected by using data acquisition instrument. Thus, the deformation and failure information of coal and rock mass can be obtained from final signals.

Under uniaxial compression, the displacement control was adopted and the displacement rate was $0.02 \mathrm{~mm} / \mathrm{s}$. The charge signal sampling frequency was set to $2500 \mathrm{~Hz}$. The charge induction probe was placed on both sides of the sample, about 5 10 $\mathrm{mm}$ away from the surface of sample, as shown in Figure 5.

The specific steps of the test are as follows:

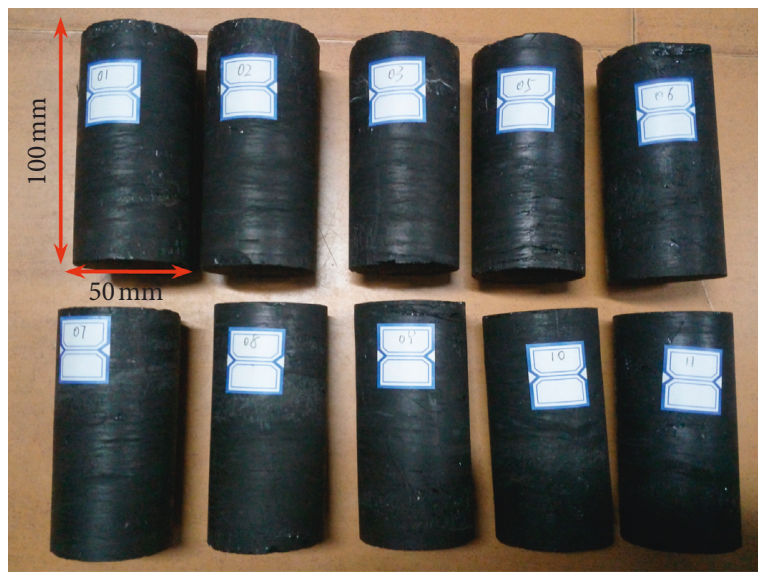

Figure 2: Coal samples.

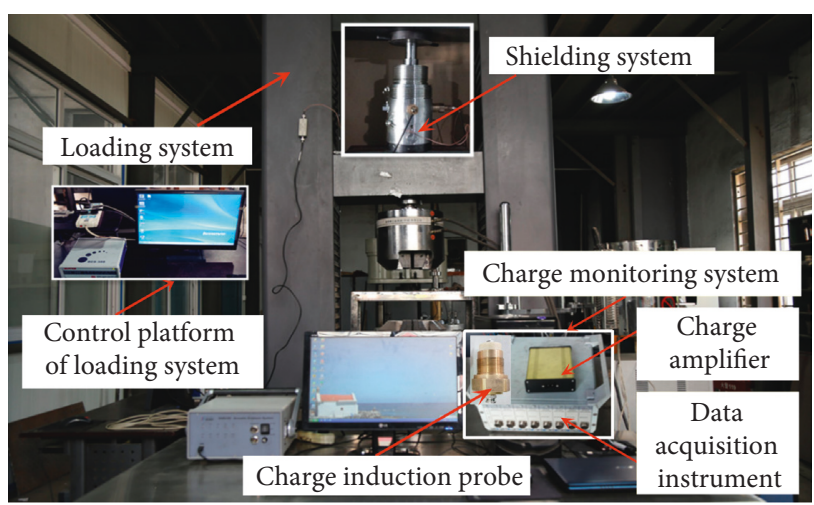

Figure 3: Experiment system.

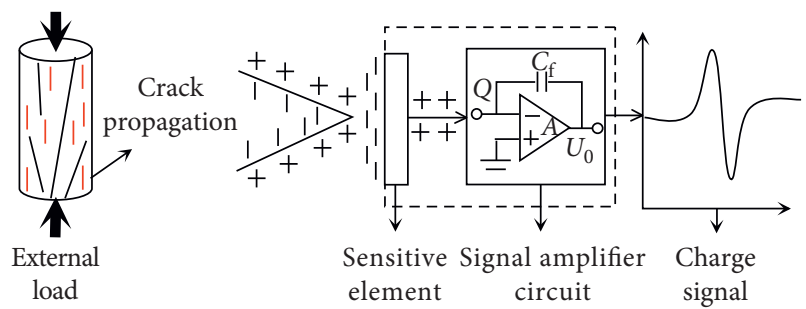

FIgURE 4: Coal-rock charge induction diagram.

(1) Install all test equipment and ensure operation of the equipment.

(2) Place a coal sample into the shield cylinder and pad the insulation paper between the coal sample and the pressure head to prevent charge overflow. Debug equipment and set parameters.

(3) Start the loading system first and then the charge monitoring system.

(4) Store the test result. Take photos of coal sample destruction and process the data.

\section{Experiment Results and Analysis}

Figure 6 is the stress-charge curve with time of coal samples under uniaxial compression. Because of the similarity of test 


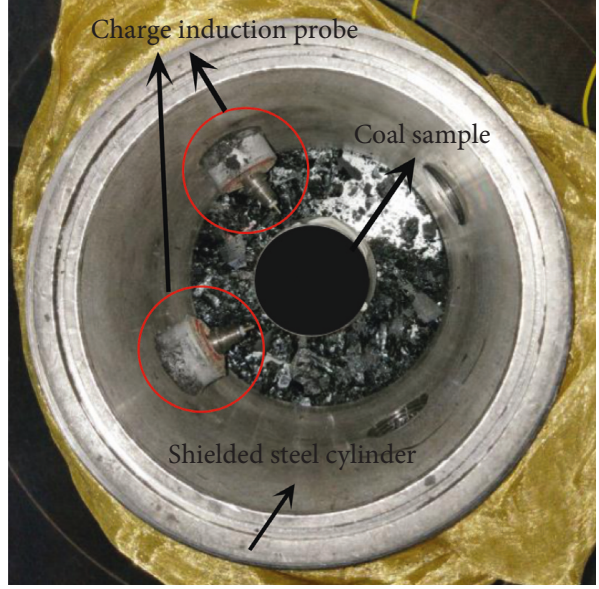

FIGURE 5: Charge induction probe arrangement.

results and the limitation of space, six representative samples were selected to illustrate the test results.

4.1. Charge Law of Coal Sample Fracture Process. Figure 6 demonstrates that the generation of charge signals is in good agreement with the stress mutation. According to the variation characteristics of the whole time-stress curve of coal sample failure, the deformation and failure process of coal sample can be roughly divided into three stages: compaction elasticity $\left(0 \sim 70 \% \sigma_{\mathrm{c}}\right)$, reinforcement damage (70\% 100\% $\left.\sigma_{\mathrm{c}}\right)$, and postpeak failure stage $\left(100 \% \sim 0 \sigma_{\mathrm{c}}\right)$. In the compacting elasticity stage, due to low extension of cracks, cumulative damage and the area of fracture surface formed are smaller, and weak friction and dislocation reveal there are fewer free charges. Therefore, charge signals remain relatively stable at this stage, and only a small amount of low charge signals are generated.

As shown in Figure 6, when it enters the reinforcement damage stage, the deformation begins to accelerate with the increase of stress. A lot of cracks converge and penetrate continuously; therefore, the cumulative damage increases. The friction degree among particles increases gradually, which increases the number of free charges escaping from bound charges in coal and rock grains and leads to the increase of frequency and amplitude of charge signals. Figure 6 shows that the stress reaches about $70 \sim 80 \% \sigma_{c}$ at the initial stage of reinforcement damage, and there are continuous high charge signals. Therefore, the generation of continuous high charge signals can be used as the precursor information for the beginning of damage degradation and unstable cracking in the inner of coal sample.

As it can be seen in Figure 6, at postpeak failure stage, the local rupture of the bearing structural plane is frequent. During the rupture process, due to the conduction of internal and external cracks, a large number of electrons emitted from internal and external crack tips fly directly into the air, and the escape of a large number of electrons causes a certain amount of charge to accumulate at the crack tip. Therefore, there is obvious charge signals generation in postpeak failure stage and charges decrease gradually with the decrease of stress.
4.2. Verification of Stress-Charge Relationship Formula of Coal Mass under Uniaxial Compression. The cumulative charge in the whole failure process of coal sample was counted and plotted in a time-cumulative charge curve to verify the feasibility of the stress-charge relationship established, as shown in Figure 6. As it can be seen in Figure 6, the cumulative charge curve is relatively stable in the compacting elastic stage, and it begins to rise obviously at reinforcement damage stage and postpeak failure stage. There is a strong correspondence between the change of cumulative charge and stress mutation, and the reduction of stress corresponds to the obviously rising stage of the cumulative charge curve.

Table 1 lists the cumulative charge at different stress levels $\left(10 \% \sigma_{c}, 20 \% \sigma_{c}, 30 \% \sigma_{c}, \ldots, 100 \% \sigma_{c}\right)$ before stress peak of coal samples to study. As can be seen in Table 1, as stress increases, cumulative charge increases gradually. Figure 7 demonstrates that the relationship between stress and cumulative charge each coal sample is fitted with a cubic polynomial formula, with the great determination $Q=a \sigma^{3}+$ $b \sigma^{2}+c \sigma+d$ ( $Q$ is the cumulative charge, $\sigma$ is the loading stress, and $a, b, c$, and $d$ are constant).

The above results show that there is a good correlation between stress and cumulative charge of coal samples during uniaxial compression, which is consistent with the results of stress-charge theoretical relationship formula established previously. As shown in Figure 7, there is an "inflection point" in the cumulative charge curve with the change of stress, and the inflection point generally occurs at 70 80\% $\sigma_{c}$. After inflection point, it is the reinforcement damage stage, and the internal cracks of coal sample continue to converge and penetrate until instability occurs. Therefore, the inflection point of the cumulative charge curve can be used as the "starting point" for the interior damage and deterioration of coal samples until failure.

\section{Charge Monitoring Experiment in Field}

In order to verify the reliability of the stress-charge theoretical relationship formula and the results of laboratory tests, field experiment of charge monitoring was carried out.

5.1. Charge Monitoring Equipment. The charge monitoring equipment used in this field test is an independently developed portable coal and rock charge monitor, as shown in Figure 8 .

It consisted of a charge sensor and a data acquisition instrument. It had the characteristics of visualization, multichannel, and portable. It can display the change law of charge signal in real time and grasp the fractured state of coal and rock in time. It had four monitoring channels, which can realize simultaneous monitoring of multiple measuring points in the underground. It was small in size, $20 \mathrm{~cm}$ in length, $15 \mathrm{~cm}$ in width, $10 \mathrm{~cm}$ in height, and $2 \mathrm{~kg}$ in weight, so it is easy to carry.

5.2. Monitoring Site and Monitoring Point Layout. The monitoring site was selected in the conveyor roadway of $\mathrm{J}_{16}$ - 

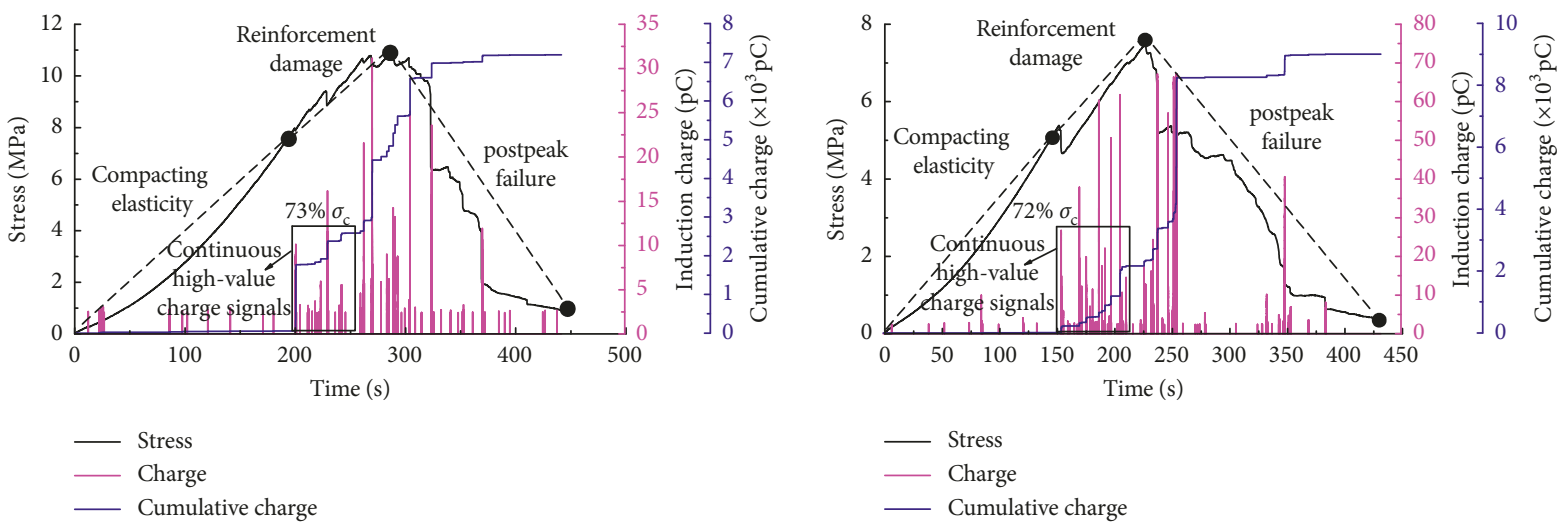

(a)
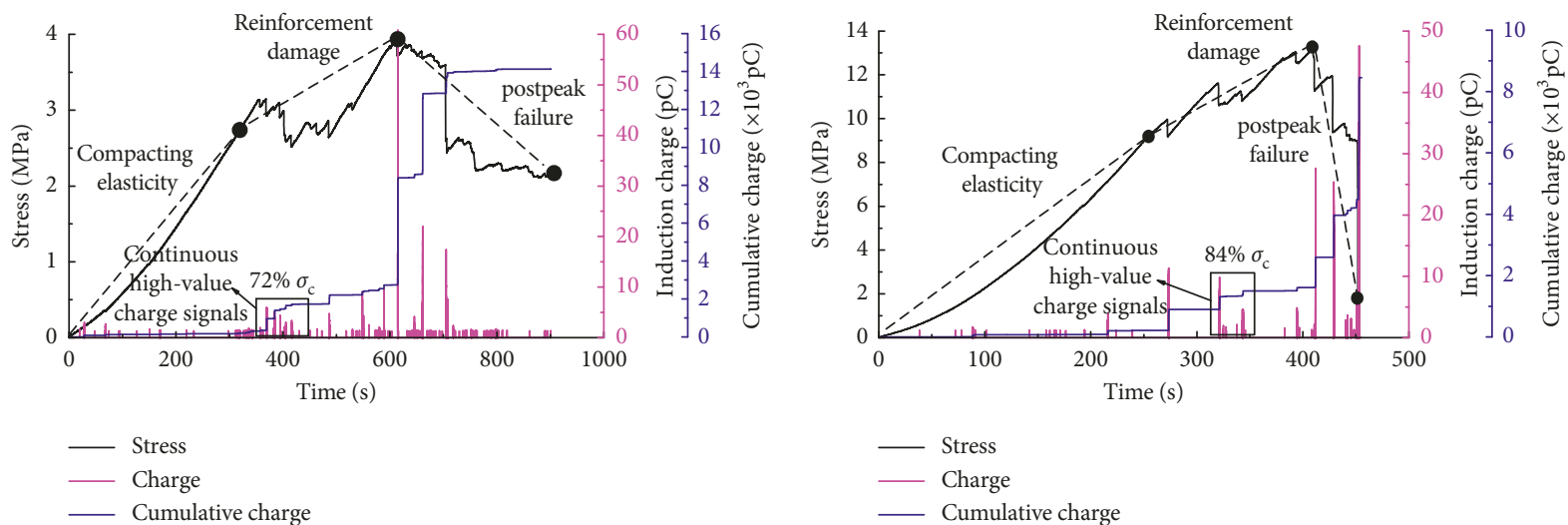

(c)

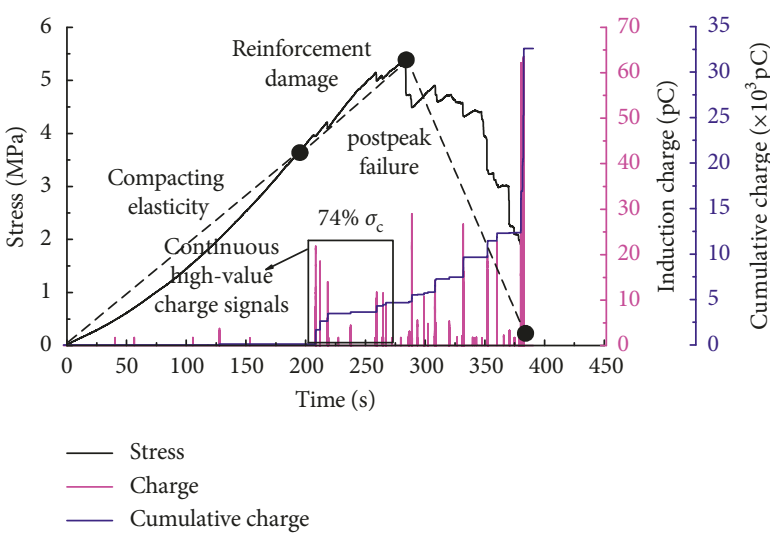

(e)

(d)

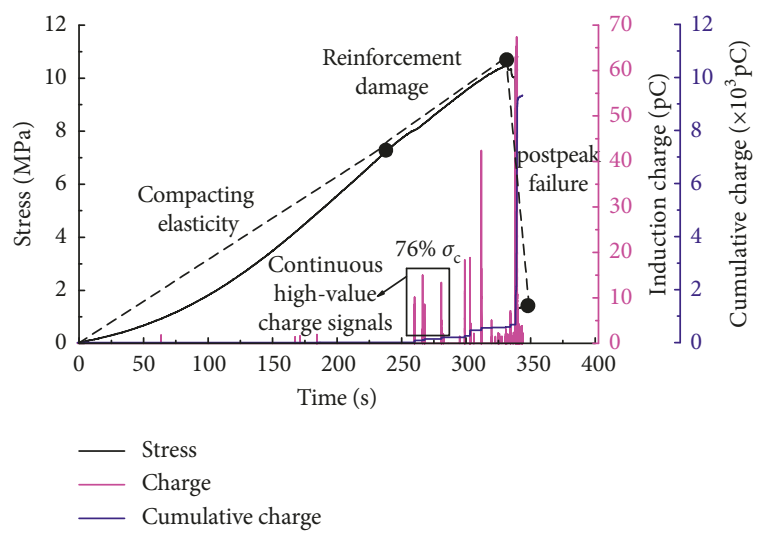

(f)

Figure 6: Charge-stress-time curve of coal samples under uniaxial compression. (a) Sample 1. (b) Sample 2. (c) Sample 3. (d) Sample 4. (e) Sample 5. (f) Sample 6.

17-24030 working face of Pingdingshan No. 11 Coal Mine. Monitoring points were set as shown in Figure 9.

Starting from the coal mining face $80 \mathrm{~m}$, a charge monitoring point was arranged every $10 \mathrm{~m}$, and a total of 10 monitoring points were arranged. The depth of each monitoring drilling was $2 \mathrm{~m}$, and the distance between monitoring drilling and floor was about $1.5 \mathrm{~m}$. The charge sensors were installed at the bottom of monitoring drilling, and the shielding copper mesh was plugged into the orifice of monitoring drilling. The monitoring time of each monitoring point was $5 \sim 10 \mathrm{~min}$.
5.3. Monitoring Results and Analysis. There was a roof falling on the night of the second day of monitoring. This section mainly studies the variation of charge signal before and after roof falling and the relationship between spatial variation trend of charge and the distribution characteristics of advanced abutment pressure. Figure 10 shows the variation of real-time charge and average charge at each monitoring point before and after roof falling.

The roof falling occurred between No. 5 and No. 6 measuring points about $118 \mathrm{~m}$ from the working face. In Figure 10(a), there is no obvious regularity of charge at each 
TABLE 1: Statistical results of prepeak stress and cumulative charge of coal samples.

\begin{tabular}{cccccccccccc}
\hline \multicolumn{2}{c}{ Stress percentage } & $10 \% \sigma_{\mathrm{c}}$ & $20 \% \sigma_{\mathrm{c}}$ & $30 \% \sigma_{\mathrm{c}}$ & $40 \% \sigma_{\mathrm{c}}$ & $50 \% \sigma_{\mathrm{c}}$ & $60 \% \sigma_{\mathrm{c}}$ & $70 \% \sigma_{\mathrm{c}}$ & $80 \% \sigma_{\mathrm{c}}$ & $90 \% \sigma_{\mathrm{c}}$ & $100 \% \sigma_{\mathrm{c}}$ \\
\hline \multirow{2}{*}{ Sample 1 } & $\sigma(\mathrm{MPa})$ & 1.080 & 2.160 & 3.240 & 4.320 & 5.400 & 6.480 & 7.560 & 8.640 & 9.720 & 10.800 \\
& $\mathrm{Q}(\mathrm{pC})$ & 26.71 & 26.71 & 42.30 & 45.05 & 48.02 & 50.71 & 53.28 & 1774.63 & 2544.51 & 2911.13 \\
\hline \multirow{2}{*}{ Sample 2 } & $\sigma(\mathrm{MPa})$ & 0.750 & 1.500 & 2.250 & 3.000 & 3.750 & 4.500 & 5.250 & 6.000 & 6.750 & 7.500 \\
& $\mathrm{Q}(\mathrm{pC})$ & 2.45 & 7.80 & 10.63 & 31.37 & 31.37 & 104.13 & 106.83 & 5214.90 & 11922.31 & 23113.03 \\
\hline \multirow{2}{*}{ Sample 3 } & $\sigma(\mathrm{MPa})$ & 0.390 & 0.780 & 1.170 & 1.560 & 1.950 & 2.340 & 2.730 & 3.120 & 3.510 & 3.900 \\
& $\mathrm{Q}(\mathrm{pC})$ & 124.68 & 128.62 & 152.15 & 152.15 & 162.76 & 162.76 & 192.06 & 307.78 & 2452.7 & 2735.14 \\
\hline \multirow{2}{*}{ Sample 4 } & $\sigma(\mathrm{MPa})$ & 1.313 & 2.626 & 3.939 & 5.252 & 6.565 & 7.878 & 9.191 & 10.504 & 11.817 & 13.130 \\
& $\mathrm{Q}(\mathrm{pC})$ & 1.17 & 69.21 & 70.41 & 77.44 & 81.06 & 205.19 & 206.39 & 900.06 & 1324.27 & 1612.18 \\
\hline \multirow{2}{*}{ Sample 5 } & $\sigma(\mathrm{MPa})$ & 0.531 & 1.062 & 1.593 & 2.124 & 2.655 & 3.186 & 3.717 & 4.248 & 4.779 & 5.310 \\
& $\mathrm{Q}(\mathrm{pC})$ & 1.78 & 3.55 & 3.55 & 101.77 & 101.77 & 103.47 & 103.47 & 3460.46 & 3627.82 & 4661.03 \\
\hline \multirow{2}{*}{ Sample 6 } & $\sigma(\mathrm{MPa})$ & 1.050 & 2.100 & 3.150 & 4.200 & 5.250 & 6.300 & 7.350 & 8.400 & 9.450 & 10.500 \\
& $\mathrm{Q}(\mathrm{pC})$ & 3.57 & 3.57 & 3.57 & 3.57 & 39.57 & 39.57 & 39.57 & 1387.99 & 1977.44 & 5882.96 \\
\hline
\end{tabular}

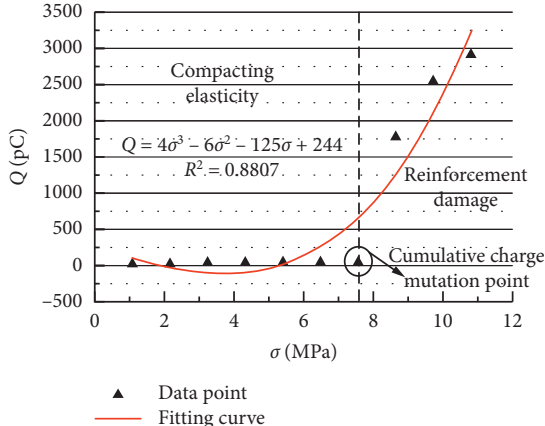

(a)

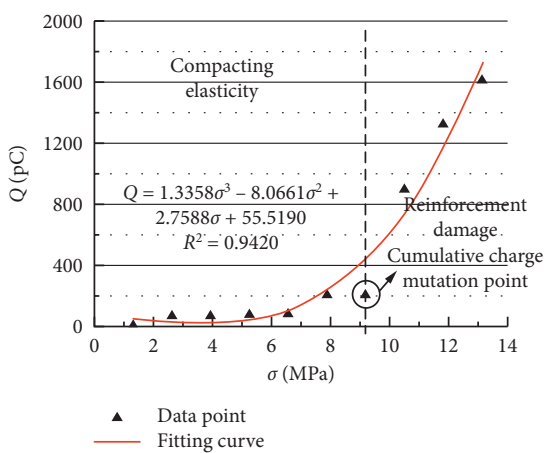

(d)

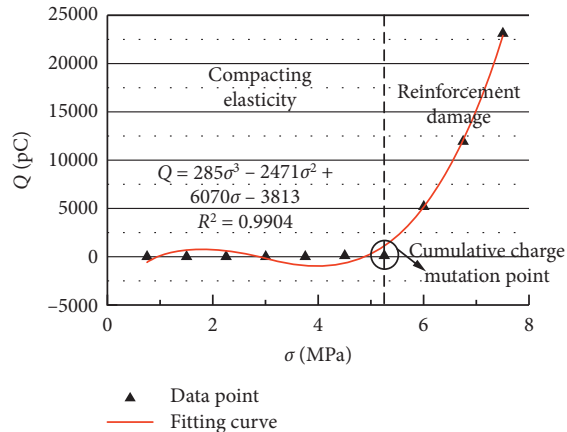

(b)

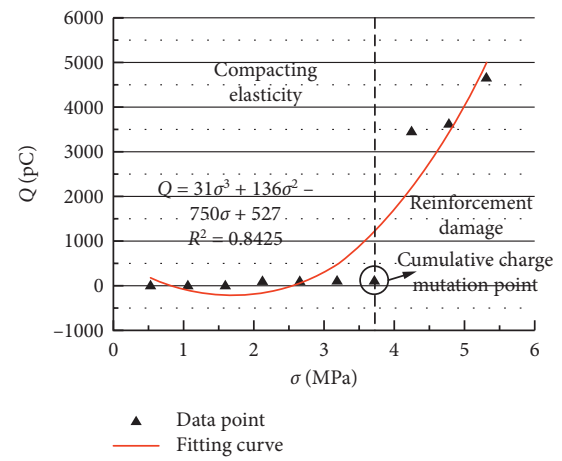

(e)

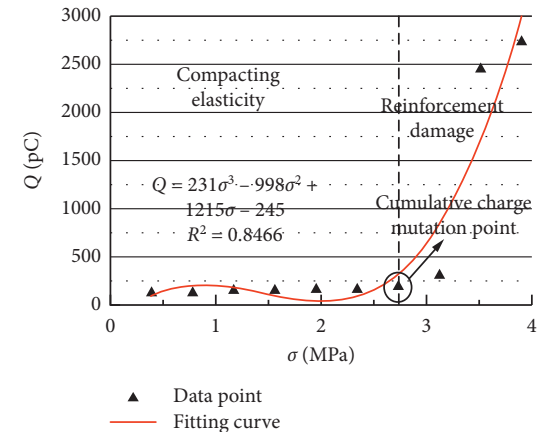

(c)

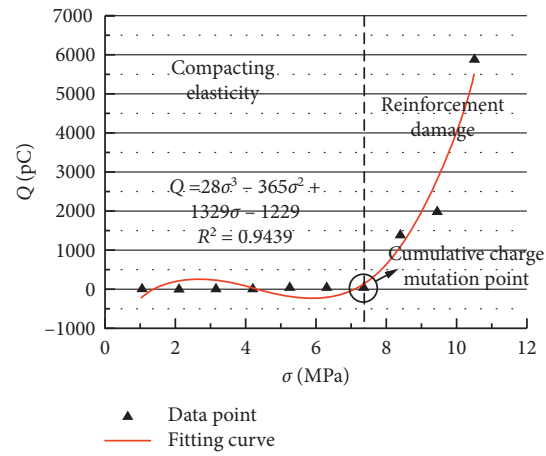

(f)

FIGURE 7: Fitting relationship between stress and cumulative charge of coal samples under uniaxial compressive. (a) Sample 1. (b) Sample 2. (c) Sample 3. (d) Sample 4. (e) Sample 5. (f) Sample 6.

monitoring point one day before top falling. The maximum value of average charge is $105.5 \mathrm{pC}$ at No. 6 monitoring point $130 \mathrm{~m}$ away from working face. The average value of charge at the adjacent No. 5 monitoring point is also large, which is $103.7 \mathrm{pC}$.

In Figure 10(b), the day of the roof falling, the charge of No. 1 No. 4 monitoring points has an obviously decreasing trend with the increase of distance from working face. However, at No. 5 monitoring point $116 \mathrm{~m}$ away from the working face, the charge increases suddenly and lasts until No. 6 monitoring point. At No. 7 monitoring point, the charge decreases slightly, and then the charge of each monitoring point decreases gradually.
In Figure 10(c), one day after roof falling, the charge of No. 5 and No. 6 monitoring points decreases significantly. In Figures $10(\mathrm{~d})$ and $10(\mathrm{e})$, on the 2 nd and $3 \mathrm{rd}$ day after the roof fall, the charge of No. 5 and No. 6 monitoring points continues to decrease gradually. With the increase of the distance from the working face, the charge of each measuring point decreases gradually.

In summary, the charge of No. 5 and No. 6 measuring points in the roof falling area changed obviously before and after the roof falling occurred. Figure 11 shows the continuous temporal variation of charge at No. 5 and No. 6 measuring points. We can find that the charge at No. 5 and No. 6 measuring points increased sharply before roof falling, 


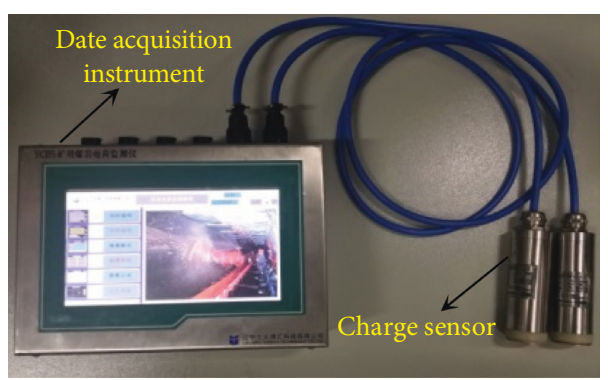

Figure 8: Portable coal and rock charge monitor.

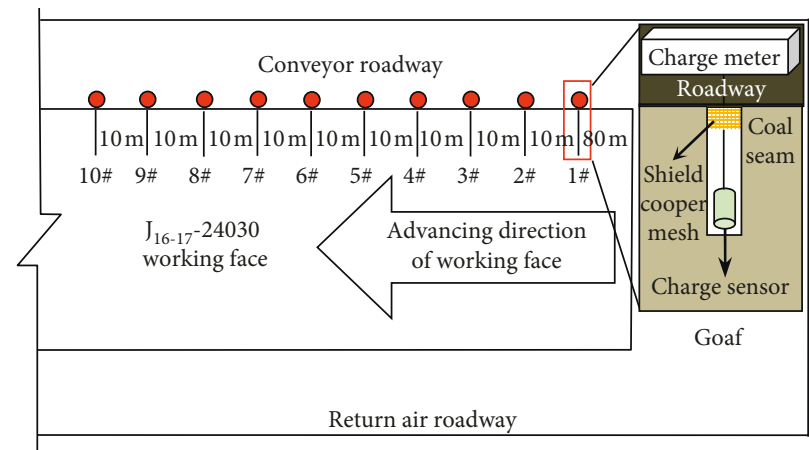

Charge measuring point

FIGURE 9: Charge monitoring point layout map.

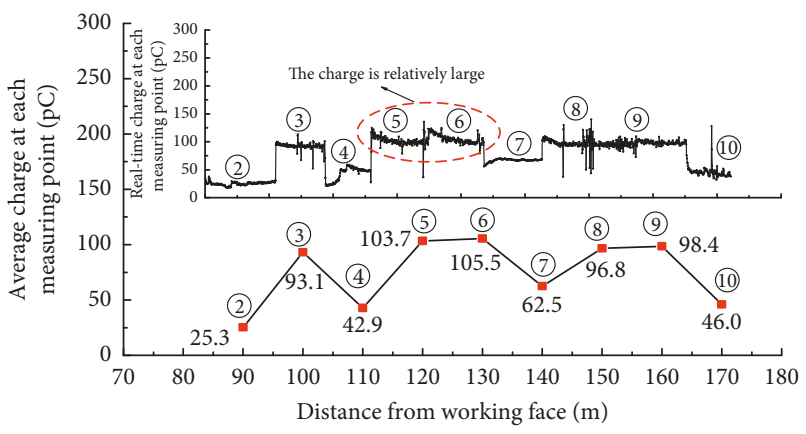

(a)

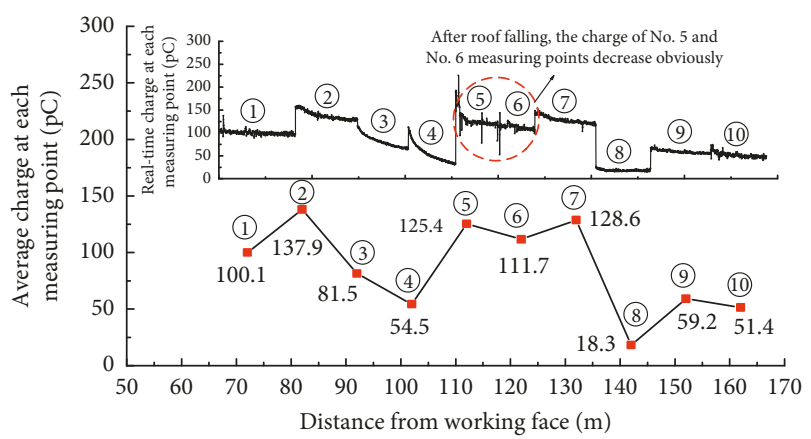

(c)

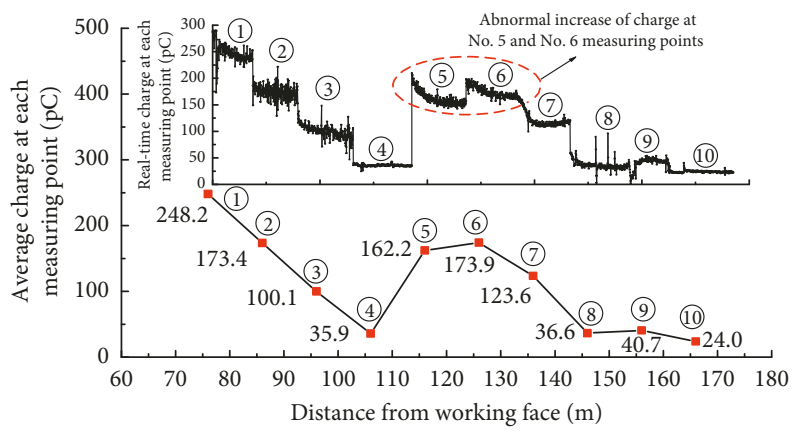

(b)

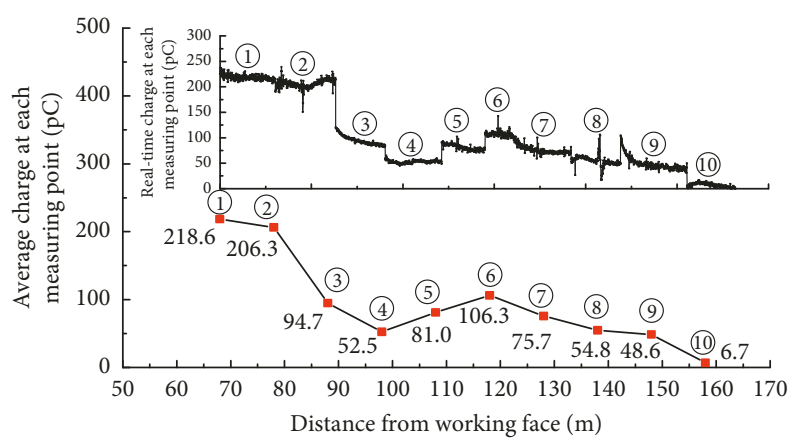

(d)

Figure 10: Continued. 


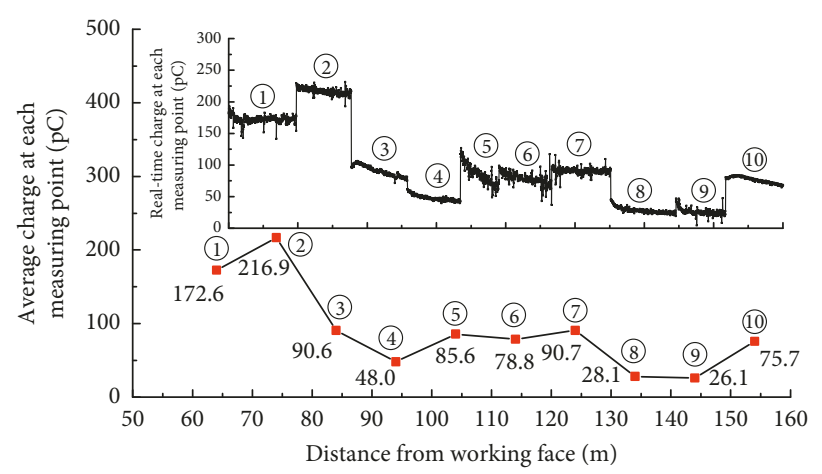

(e)

Figure 10: Monitoring results of charge at each monitoring point. (a) Day 1. (b) Day 2. (c) Day 3. (d) Day 4. (e) Day 5.

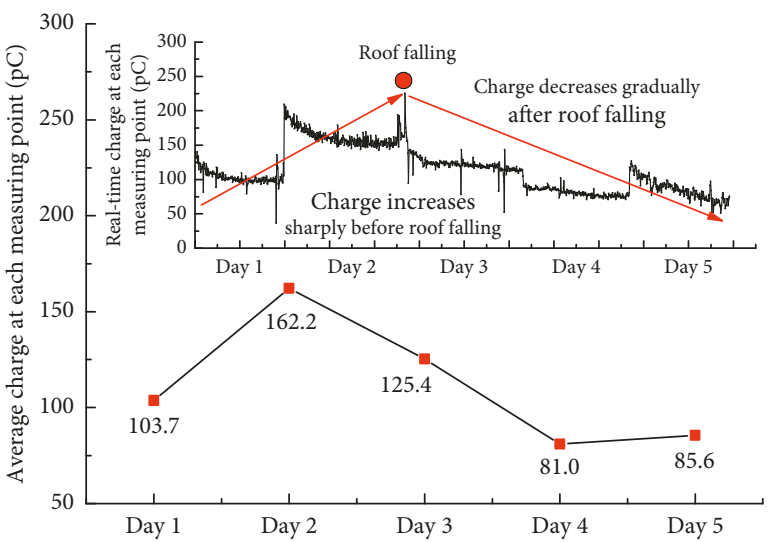

(a)

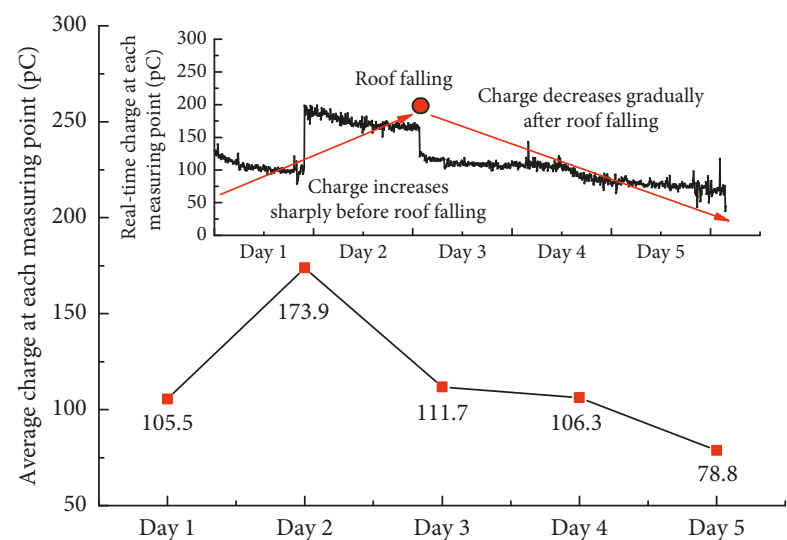

(b)

Figure 11: Variation of charge before and after roof falling at No. 5 and No. 6 measuring points. (a) No. 5 measuring points. (b) No. 6 measuring points.

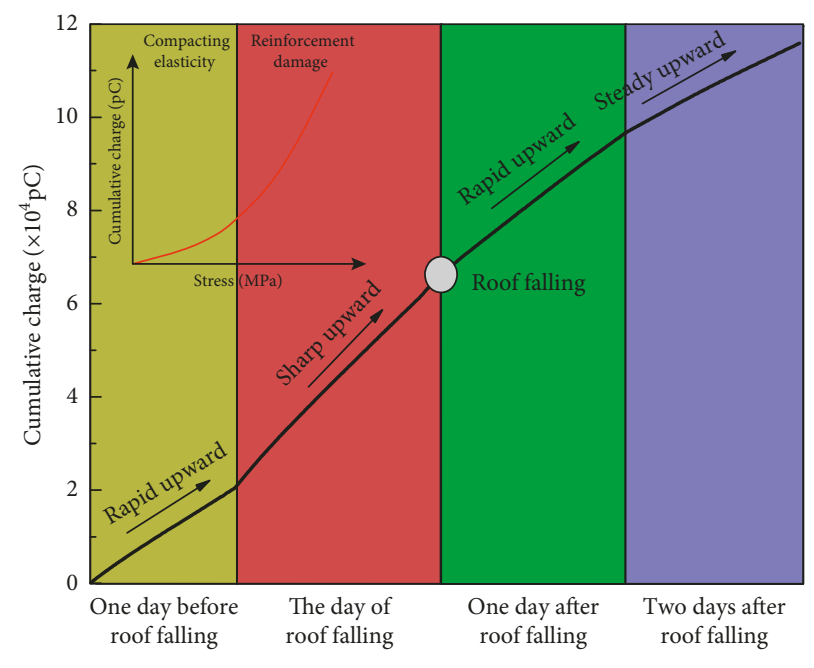

- Cumulative charge curve

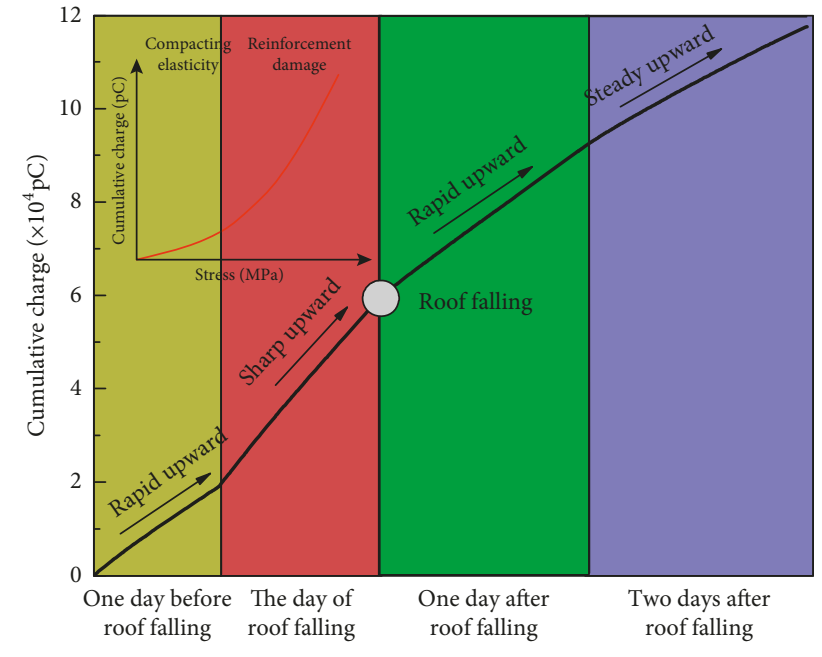

Cumulative charge curve

(a)

(b)

FIGURE 12: Cumulative charge curve. (a) No. 5 monitoring point. (b) No. 6 monitoring point. 


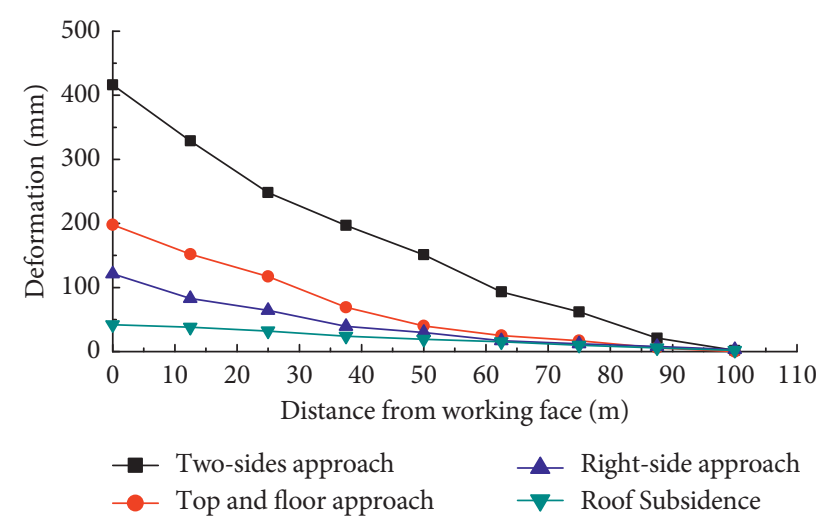

Figure 13: Deformation of conveyor roadway cross section at No. 7 measuring point of $\mathrm{J}_{16-17}-24030$ working face.

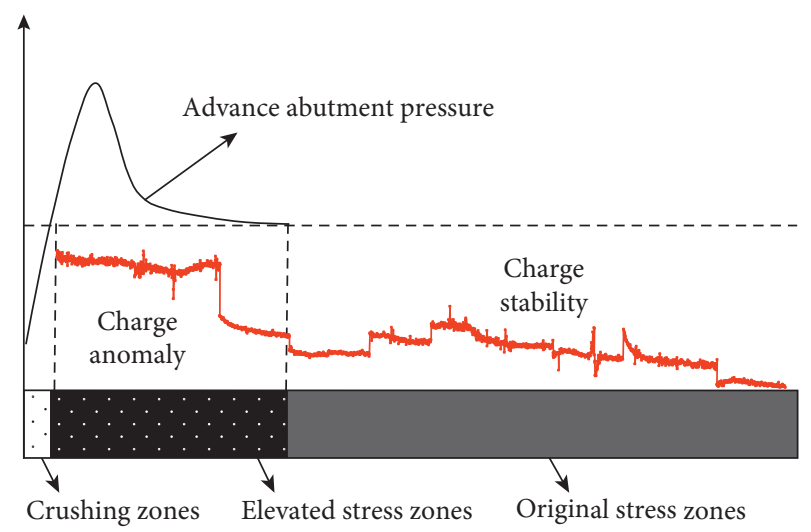

FIGURE 14: Relationship between advance abutment pressure and charge in front working face.

and the average charge increased by $56.4 \%$ and $64.8 \%$, respectively. Therefore, a certain percentage of the charge increment at a single point can be taken as an early warning index for the mine pressure appearance in working face preliminary, and the critical value is $56.4 \sim 64.8 \%$. After the roof falling, the charge of No. 5 and No. 6 measuring points decreases gradually.

According to the variation characteristics of charge signals of No. 5 and No. 6 monitoring points before and after roof falling, the cumulative charge curves of No. 5 and No. 6 monitoring points before and after roof falling were drawn, as shown in Figure 12. Figure 12 shows that the cumulative charge curve shows a rapid upward trend one day before roof falling and a sharp upward trend on the day of roof falling. According to the laboratory results in Figure 7, the sharp upward of cumulative charge indicates that coal mass has entered the reinforcement damage stage and the stress level is relatively high. This is probably the main reason for the roof falling that day. It also proves the feasibility of stresscharge relationship formula established (formula (12)). As it can be seen in Figure 12, the cumulative charge curve shows a rapid upward trend one day after roof falling and a steady upward trend two days after roof falling. This is a process of gradual release of energy. Therefore, the overall variation characteristics of cumulative charge curve can identify the stress level and the degree of damage and fracture of coal mass to a certain extent. At the same time, the sharp increase of cumulative charge can be used as precursor information for the mine pressure appearing, but a large number of experiments need to be carried out to continuously verify it.

Figure 13 is the monitoring results of cross-sectional deformation of No. 7 monitoring point in the conveyor roadway of $J_{16-17}-24030$ working face. It can be seen that the deformation begins to change when the distance between No. 7 measuring point and working face is about $100 \mathrm{~m}$. With the advance of the working face, the deformation increases gradually. So, the influence range of advance abutment pressure in $\mathrm{J}_{16-17}-24030$ working face is about $100 \mathrm{~m}$. According to the mine pressure and strata control theory, the area in front of coal mining face can be divided into crushing zones, elevated stress zones, and original stress zones in turn, as shown in Figure 14. It can be found that from Figures 10(b)-10(e) that the charge of No. 1 No. 3 measuring points in the range of $100 \mathrm{~m}$ in front of the working surface is relatively large, while the charge of other points is relatively small. The effect of roof falling on charge is not considered here. Therefore, the spatial variation trend of charge at each monitoring point is closely related to the distribution characteristics of advanced abutment pressure. In the elevated stress zones, the average charge is larger, while in the original stress region, the average charge is smaller, as shown in Figure 14. Therefore, the magnitude and position of the average charge can be used to reflect the stress concentration degree and stress distribution characteristics in front of working face.

\section{Conclusion}

In this paper, the authors establish the stress-charge relationship formula of coal mass, study the quantitative relationship between stress and cumulative charge under uniaxial compression through laboratory experiments, and perform the field charge monitoring test with the independently developed device. The major conclusions are as follows:

(1) There is a nonlinear relationship between loading stress and cumulative charge of coal mass under uniaxial compression, which can be expressed by polynomials.

(2) With the increasing of stress, the frequency and intensity of charge signals increase gradually. The appearance of "continuous high charge signal" can be used as precursor information for coal samples to enter reinforcement damage stage and unstable fracture.

(3) The experimental fitting results between stress and cumulative charge of coal samples conform to a cubic polynomial relationship, and the fitting formula is $Q=a \sigma^{3}+b \sigma^{2}+c \sigma+d$, which verifies the feasibility of stress and charge relationship formula. The inflection point of cumulative charge curve can be regarded as the "starting point" for the interior 
damage and deterioration of coal samples until failure.

(4) The spatial variation trend of charges at each monitoring point is closely related to the distribution characteristics of advance abutment pressure. The overall variation characteristics of cumulative charge curve can identify stress level and the degree of damage and fracture of coal mass to a certain extent.

(5) The magnitude and position of average charge and the upward trend of cumulative charge can be used to identify the stress concentration degree and stress distribution characteristics in front of working face. However, it is also necessary to analysis and summarize the intrinsic relationship between temporal and spatial distribution of charge signal and pressure appearing in the working face continuously.

The charge induction method is a new rock burst prediction method. In this paper, the relationship between stress and charge of coal mass under uniaxial compression is studied. However, the relationship between stress and charge under triaxial compression is still unknown. This will be the next step for research, including theoretical analysis, laboratory experiment, and field monitoring.

\section{Data Availability}

The data used to support the findings of this study are available from the first author upon request.

\section{Conflicts of Interest}

The authors declare that there are no conflicts of interest regarding the publication of this paper.

\section{Acknowledgments}

The authors would like to acknowledge the financial support of the National Program on Key Basic Research Project (Grant no. 2016YFC0801403-4) and National Natural Science Foundation of China (Grant nos. 51974186 and 51974147).

\section{References}

[1] Z. Li, L. Zhu, W. Yin, and Y. Song, "Study on monitoring rock burst through drill pipe torque," Shock and Vibration, vol. 2015, Article ID 371948, 8 pages, 2015.

[2] T. Li, M. F. Cai, and M. Cai, "A review of mining-induced seismicity in China," International Journal of Rock Mechanics and Mining Sciences, vol. 44, no. 8, pp. 1149-1171, 2007.

[3] J. He, L.-M. Dou, W. Cai, Z.-L. Li, and Y.-L. Ding, "In situ test study of characteristics of coal mining dynamic load," Shock and Vibration, vol. 2015, Article ID 121053, 8 pages, 2015.

[4] C. G. Wen and Y. X. Wang, "Discussion of value of drilling cuttings weight index," Journal of Mining Safety and Environment Protection, no. 3, pp. 32-34, 1998.

[5] J. Franklin, "Suggested methods for pressure monitoring using hydraulic cells," International Journal of Rock Mechanics and Mining Sciences \& Geomechanics Abstracts, vol. 17, no. 2, pp. 117-127, 1980.
[6] R. D. Russell, M. Maxwell, K. E. Butler, and A. Kepic, "Electromagnetic responses from seismically excited targets A: piezoelectric phenomena at Humboldt Australia," Exploration Geophysics, vol. 23, no. 2, pp. 281-286, 1992.

[7] G. O. Cress, B. T. Brady, and G. A. Rowell, "Sources of electromagnetic radiation from fracture of rock samples in the laboratory," Geophysical Research Letters, vol. 14, no. 4, pp. 331-334, 1987.

[8] D. V. Alekseev, P. V. Egorov, and V. V. Ivanov, "Mechanisms of electrification of cracks and electromagnetic precursors of rock fracture," Journal of Mining Science, vol. 28, no. 6, pp. 515-519, 1993.

[9] Y. Enomoto and H. Hashimoto, "Electric charge fluctuations as detected prior to earthquake occurrence near Tsukuba in Japan," in Proceedings of the International Workshop on Electromagnetic Phenomena Related to Earthquake Prediction, Tokyo, Japan, September 1993.

[10] U. Nitsan, "Electromagnetic emission accompanying fracture of quartz-bearing rocks," Geophysical Research Letters, vol. 4, no. 8, pp. 333-336, 1977.

[11] T. Ogawa, K. Oike, and T. Miura, "Electromagnetic radiations from rocks," Journal of Geophysical Research, vol. 90, no. D4, pp. 6245-6250, 1985.

[12] V. S. Kuksenko, K. F. Makhmudov, and A. V. Ponomarev, "Relaxation of electric fields induced by mechanical loading in natural dielectrics," Physics of the Solid State, vol. 39, no. 7, pp. 1065-1066, 1997.

[13] P. Varotsos, V. Hadjicontis, and A. S. Nowick, "The physical mechanism of seismic electric signals," Acta Geophysical Polonica, vol. 49, pp. 415-421, 2001.

[14] F. Vallianatos and A. Tzanis, "Electric current generation associated with the deformation rate of a solid: preseismic and coseismic signals," Physics and Chemistry of the Earth, vol. 23, no. 9-10, pp. 933-938, 1998.

[15] F. Vallianatos and A. Tzanis, "A model for the generation of precursory electric and magnetic fields associated with the deformation rate of the earthquake focus," in Seismic Atmospheric \& Ionospheric Electromagnetic Phenomena, M. Hayakawa, Ed., Terra Scientific Publishing Co., Tokyo, Japan, 1999.

[16] F. Vallianatos, D. Triantis, A. Tzanis, C. Anastasiadis, and I. Stavrakas, "Electric earthquake precursors: from laboratory results to field observations," Physics and Chemistry of the Earth, Parts A/B/C, vol. 29, no. 4-9, pp. 339-351, 2004.

[17] D. Triantis, C. Anastasiadis, and I. Stavrakas, "The correlation of electrical charge with strain on stressed rock samples," Natural Hazards and Earth System Sciences, vol. 8, no. 6, pp. 1243-1248, 2008.

[18] D. Triantis, I. Stavrakas, C. Anastasiadis, A. Kyriazopoulos, and F. Vallianatos, "An analysis of pressure stimulated currents (PSC), in marble samples under mechanical stress," Physics and Chemistry of the Earth, Parts A/B/C, vol. 31, no. 4-9, pp. 234-239, 2006.

[19] I. Stavrakas, C. Anastasiadis, D. Triantis, and F. Vallianatos, "Piezo stimulated currents in marble samples: precursory and concurrent-with-failure signals," Natural Hazards and Earth System Science, vol. 3, no. 3-4, pp. 243-247, 2003.

[20] Z. J. Sun, L. H. Wang, and H. Gao, "Electromagnetic emission and light radiation during fracture of rock samples," Chinese Journal of Geophysics, vol. 29, no. 5, pp. 491-495, 1986, in Chinese.

[21] X. Q. He and M. J. Liu, Electromagnetic Dynamics of GasBearing Coal or Rock Failure, China University of Mining and Technology Press, Beijing, China, 1995, in Chinese. 
[22] X. F. Lv, Y. S. Pan, X. C. Xiao, and A. W. Wang, "Barrier formation of micro-crack interface and piezoelectric effect in coal and rock masses," International Journal of Rock Mechanics and Mining Sciences, vol. 64, pp. 1-5, 2013.

[23] Y. S. Pan, H. Luo, Z. Tang, Z. H. Li, and Y. F. Zhao, "Study of charge induction law of coal and rock mass during tensile instability and failure," Chinese Journal of Rock Mechanics and Engineering, vol. 32, no. 7, pp. 1297-1303, 2013, in Chinese.

[24] G. Wang, Y. S. Pan, and X. C. Xiao, "Study and application of failure characteristics and charge law of coal body under uniaxial loading," Rock and Soil Mechanics, vol. 40, no. 5, pp. 1-9, 2013, in Chinese.

[25] X. C. Xiao, C. Jin, X. Zhao, X. Ding, L. P. Dai, and J. Xu, "Experimental study on the charge criterion of coal-rock bodies burst tendency," Rock and Soil Mechanics, vol. 38, no. 6, pp. 1620-1628, 2017, in Chinese.

[26] H. F. Xiao, "Research on the coupling laws between EME and stress during the fracture of coal or rock," $\mathrm{Ph}$. D. thesis, China University of Mining and Technology, Beijing, China, 2003, in Chinese.

[27] D. Krajcinovic and M. A. G. Silva, "Statistical aspects of the continuous damage theory," International Journal of Solids and Structures, vol. 18, no. 7, pp. 551-562, 1982.

[28] C. A. Tang, Catastrophe in Rock Unstable Failure, China Coal Industry Press, Beijing, China, 1993, in Chinese. 


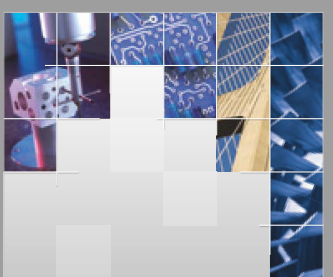

\section{Enfincering}
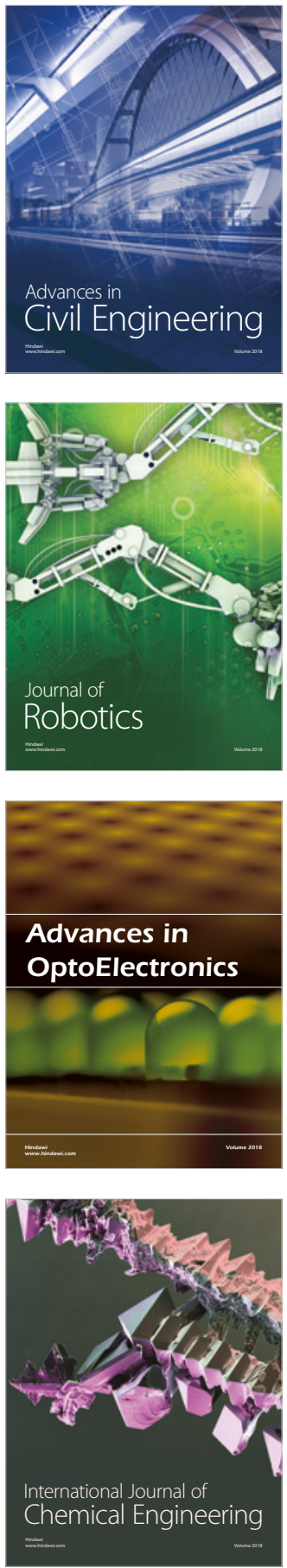

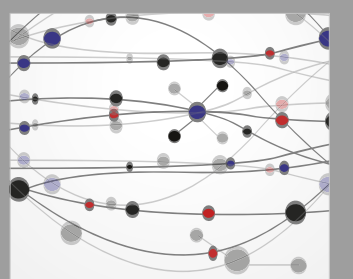

\section{Rotating \\ Machinery}

The Scientific World Journal

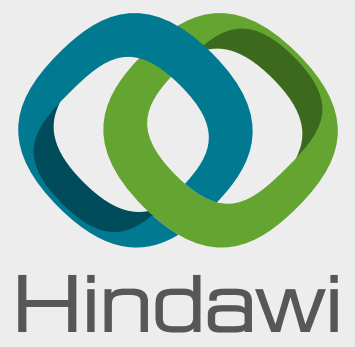

Submit your manuscripts at

www.hindawi.com
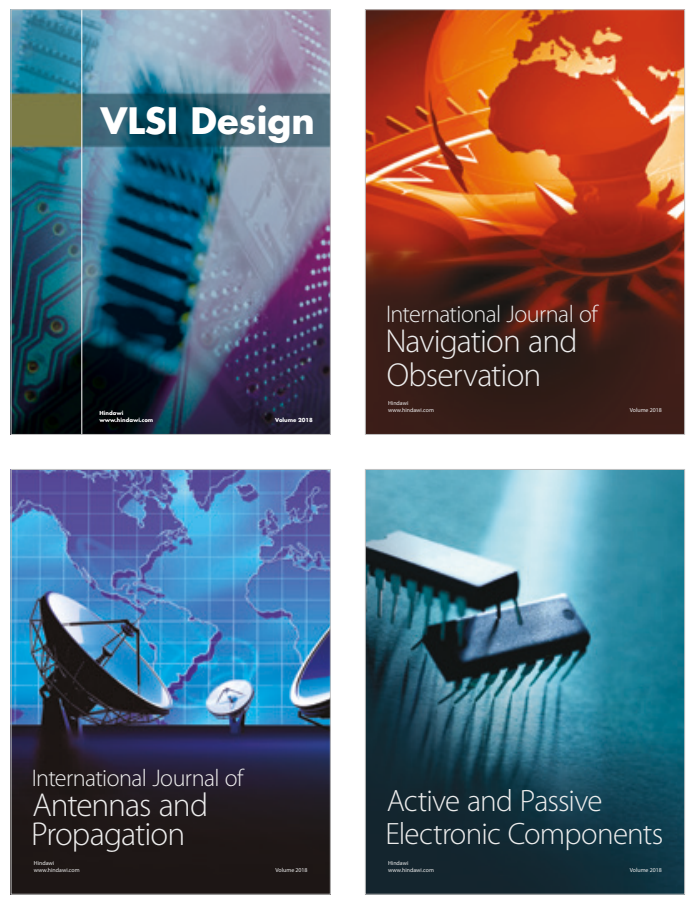
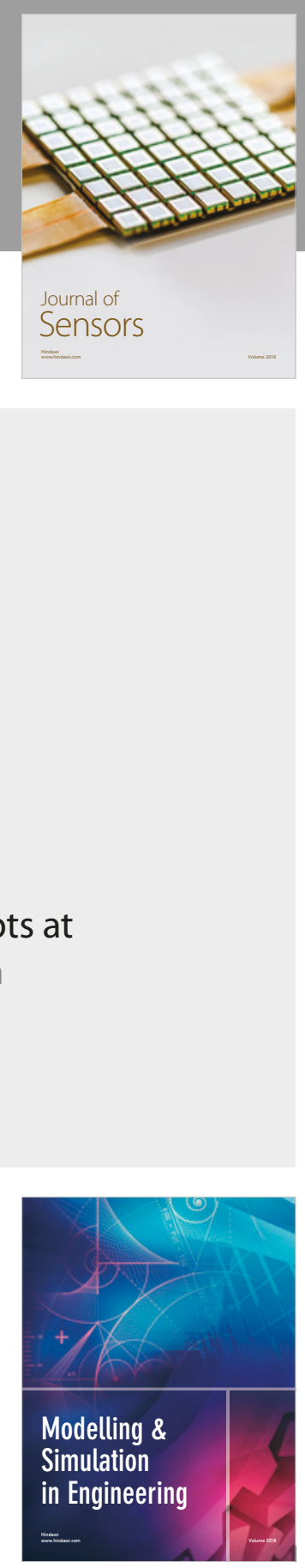

\section{Advances \\ Multimedia}
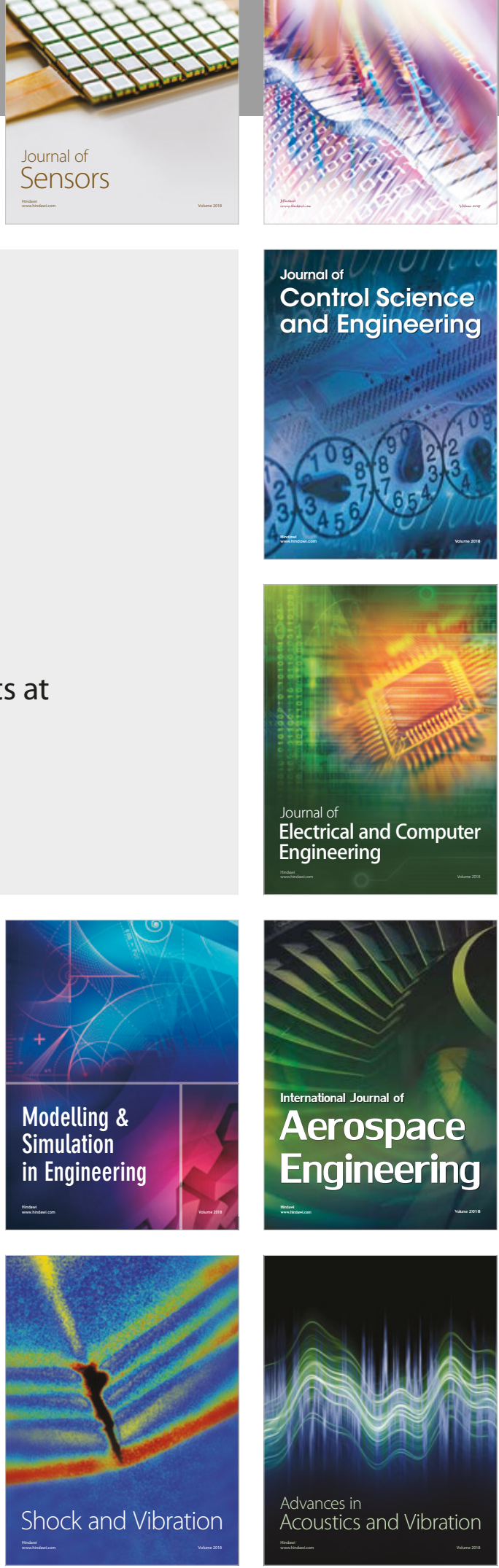